\title{
A Magia da Canção, a Invenção da Tradição e a Estruturação do Tempo entre os Shipibo, Amazônia Peruana
}

\author{
Bernd Brabec de Mori \\ Universität für Musik und darstellende Kunst Graz, Graz, Áustria \\ E-mail: leukozyt@hushmail.com
}

Tradução: Sérgio Fonseca 


\section{Resumo}

O canto dos Shipibo-Konibo (grupo indígena das terras baixas peruanas) em curas rituais revela que um marcador de tempo em sua linguagem vernacular pode se referir a um passado mítico e a um "mundo espiritual" do presente. Neste artigo serão apresentados e analisados o passado recente do grupo no que diz respeito à bebida ayahuasca, o significado de seus trançados e sua identidade "étnica". Aqui será observado que o passado é flexível, ou não fixo, permitindo alterações dependentes de narrações, de canções e de representações rituais.

Palavras-chave: Conhecimento Indígena. Shipibo-Konibo. Música Ritual. Mitologia. Futuro não Remoto.

\section{Abstract}

Shipibo-Konibo (Peruvian lowland indigenous group) singing in ritual healing reveals that a tense marker in their vernacular language can refer to both a mythical past and a present "spirit world". The group's recent past regarding the ayahuasca brew, the meaning of their patternwork, and their "ethnic" identity as a whole is presented and analyzed. It is shown that the past is flexible, or non-fixed, allowing for alterations depending on the storytelling, singing, and acting of ritual.

Keywords: Indigenous Knowledge. ShipiboKonibo. Ritual Music. Mythology. Remote Non-future. 


\section{Introdução}

$\mathrm{O}$ s Shipibo (denominação oficial: Shipibo-Konibo) abarcam cerca de 45 mil pessoas que habitam, principalmente, nas margens do rio Ucayali e seus afluentes, no leste do Peru, na Floresta Amazónica Superior ${ }^{1}$. São o maior e o único grupo fluvial da família linguística Pano. Os Shipibo são bem conhecidos pelas suas obras de arte, manifestando-se especialmente nos desenhos de padrão elaborado (chamados kené ou kewé) aplicados aos têxteis, cerâmicas e artigos de madeira esculpida. Desde aproximadamente 1965, que muita pesquisa tem sido feita entre eles, em diferentes disciplinas como arqueologia, antropologia, ou linguística. A pesquisa no campo da Etnomedicina tem sido amplamente realizada ao grupo, principalmente em relação ao uso médico ou "xamânico" de plantas, sendo o mais proeminente, o da bebida alucinogénica ayawaska (chamado nishi ou oni na língua Shipibo) $)^{2}$.

Ao contrário de muitos autores, não pretendo apresentar aqui os elementos de uma suposta "cultura Shipibo original" nem quero mostrar como os Shipibo se adaptaram à alegada moderna cultura ocidental globalizante. Em vez disso, vou derrubar os pressupostos necessários para tanto das perspetivass mencionadas: em primeiro lugar que havia uma forma, de alguma maneira "estável", de vida entre os povos indígenas antes da influência ocidental (sendo esse pressuposto uma herança do século XIX) e, em segundo lugar, que a única maneira de sobreviver dos povos indígenas é adaptar-se passivamente ao mercado, ao capitalismo e à globalização (este que é um dogma muito mais "moderno" e quase irresistível). 
$\mathrm{Eu}$ acredito que muitos povos indígenas, e os Shipibo de uma forma muito representativa, têm algumas grandes vantagens em comparação com a sociedade ocidental, devido à sua compreensão ecológica do mundo 3 e à sua inerente flexibilidade e potencial inovador. Essa flexibilidade também se estende para a conceptualização e estruturação de tempo. Na compreensão ocidental, o passado parece "solidificado": a interpretação quotidiana comum do tempo assume um passado objetivo que tinha realmente acontecido, e um processo histórico determinado pelas interpretações intersubjetivas dos restos desse passado no presente. Um “verdadeiro passado" está previsto, e a razão pela qual não se pode penetrar no manto de névoa que embaça a sua nitidez é apenas a nossa falta de provas e uma insuficiência latente nos métodos de pesquisa ou lembrança (que pode ser superada um dia). Dessa forma, uma inevitabilidade histórica do presente e, também, de alguma forma, do futuro é criada. Na sociedade Shipibo, por outro lado, parece que a necessidade de "um passado verdadeiro" não é sentida, mas quase qualquer passado pode ser projetado a partir do presente. Esse processo construtivo, que irei argumentar, não é definido analisando vestígios (que na verdade são raros em materiais e formas intangíveis), mas refletindo e recriando o presente. Talvez o passado seja deixado tão aberto quanto o futuro. Nesse contexto, dois métodos indígenas parecem viáveis para melhorar, ou manipular, a situação atual de um indivíduo, uma família ou dos Shipibo como uma identidade de grupo: (i) especialistas em magia, feitiçaria e medicina (que se autodenominam médicos) podem manipular as relações entre os seres humanos e não humanos e, portanto, efetuar uma mudança na realidade (cura e feitiçaria), ou (ii) protagonistas Shipibo, representando a "sua cultura", podem contar novas narrativas sobre o passado, sobre suas tradições, histórias e conhecimento antigo que realmente os afetam e afetam o seu posicionamento parental e a performance no mercado de popularidade entre turistas e pesquisadores.

Para investigar essas questões, vou primeiro introduzir o tema da cura musical, como o observei entre os Shipibo, comparando-o com a forma como é representado na literatura mais académica e popular, extrapolando algumas diferenças. O seguinte apontamento sobre 
algumas mudanças políticas e sociais durante as últimas décadas entre os Shipibo pode ajudar a entender como essas diferenças surgiram e também vai elucidar o papel dos dois métodos de moldar a realidade presente que mencionei anteriormente: magia e narração. Finalmente, vou mostrar que na gramática Shipibo há indícios de que estes dois métodos não são tão diferentes uns dos outros como pode parecer à primeira vista.

\section{A Magia Quotidiana da Música}

Entre os Shipibo, como na maioria dos grupos indígenas vizinhos, a música tem um papel importante especialmente quando se trata de magia ou cura. Há alguma evidência ${ }^{4}$ de que antes do boom da borracha (ca. 1870-1920), músicas e performance teatral foram os aspectos mais importantes dos rituais de cura. Naquela época, tais rituais podem ter incluído muitos processos que são raros nos dias de hoje. Parece que, por exemplo, a posse ou a transformação em animais desempenhou um papel muito mais elevado e música vocal era o modo preferido de comunicação com esses animais. Cantar também era a única possibilidade para os animais ou espíritos, que tomaram posse do performador, de se expressar ou transmitir a sua mensagem aos ouvintes humanos 5 .

Na terminologia e na compreensão Shipibo, não há uma distinção clara entre canções mágicas e não-mágicas. Mais precisamente, qualquer performance musical envolve algum contingente de poder mágico, pelo que não se deve cantar levianamente. Illius (1997, p. 216) explica que os Shipibo não cantam durante as atividades quotidianas (não há canções de trabalho, por exemplo) para que elas não atraiam, involuntariamente, a atenção dos não humanos. A música é considerada a língua dos espíritos e, portanto, à priori magicamente potente. As músicas executadas em festas de bebida ou para namoro, por exemplo, também carregam um certo grau de poder mágico: um homem, por exemplo, pode cantar, a fim de ter a moça que deseja apaixonada por ele. Uma mulher pode cantar para abordar a potencial compreensão do seu amante secreto, de que ela gostaria de fugir com ele para outra 
aldeia. Como é ilustrado por estes exemplos, inúmeras canções - por mais "seculares" que sejam - são pensadas de forma a lançar efeitos sobre as pessoas a quem são cantadas. Esse entendimento do efeito é codificado em linguagem metafórica. Nas letras das músicas, por exemplo, as pessoas são referidas como certos animais. Essa atribuição de identidades de animais a seres humanos não é descritiva mas sim prescritiva: o cantor, que tenta seduzir uma menina chamar-lhe-ia, por exemplo bontoish. O bontoish é um belo pássaro pequeno e, no código de letras de músicas Shipibo, é usado para tratar uma pessoa jovem, bem parecida e casável (cujo sexo é geralmente o oposto ao do cantor). Mencionar bontoish nesse contexto não descreve o comportamento da menina, mas, na verdade, prescreve-o: o cantor define a reação ideal dela para um futuro próximo por meio de nomes significativos ${ }^{6}$.

Além disso, há músicas "semi-medicinais", destinadas a "curar" alguém para se tornar um bom caçador ou um artista melhor, ou para "curar" pessoas (que são, por exemplo preguiçosas, ou muito brincalhonas com os parceiros) para que tenham um comportamento mais aceitável em termos sociais. A ideia central da eficácia nessas canções é a mesma: a atribuição precisa de identidades não-humanos para a pessoa alvo. Por último, e ainda para além daquilo que os ocidentais entendem por "medicinal", há evidências de atividades anteriores, 7 que também pode ser apelidadas de "religiosas". O ritual mochai, que já não se realiza, é quase desconhecido nos estudos antropológicos sobre a história dos Shipibo e parece ter incluído a adoração coletiva do sol, a "cura" do sol ou da lua em casos de eclipse, e em determinadas situações, a convocação de seres animais e humanos transitórios delicadamente poderosos chamados simpibo jonibo. As músicas mochai eram o coração deste ritual, realizado por grandes grupos de cantores ${ }^{8}$.

\section{Músicas Médicos e "Xamanismo Ayawaska"}

Nos rituais de cura de hoje, a importância da música é óbvia, porque as canções são cantadas em quase qualquer caso em que ocorre a cura. No entanto, essas músicas só podem ser cantadas de forma eficiente por curandeiros especializados (médicos). Esses curandeiros 
costumavam ocupar uma posição ambivalente na vida social dos Shipibo já que eram respeitados como curandeiros e ao mesmo tempo temidos como feiticeiros (isso mudou, como será mostrado mais adiante). A aplicação mais discreta das músicas medicinais é o assobio (koxonti) a fim de "carregar" uma substância de suporte (geralmente um charuto, cachimbo, um perfume, ou qualquer remédio para ser administrado a um paciente), com a potência de uma música. Assim, o médico ${ }^{9}$ tem o objeto ou substância perto de sua boca enquanto assobia a melodia. O médico não pronuncia a letra da música, mas deve pensar nos versos adequados (cf. Olsen, 1996, p. 259, em the Warao hoa songs). Em seguida, o objeto "carregado" ou a substância é fumada, aplicada ou ingerida e, com isso, o poder da canção mágica deve revelar-se e provocar os efeitos pretendidos. Esta "carga", koxonti, é mais frequentemente usada durante o dia e sem muitas preparações rituais. Pode, no entanto, também ser efetuada por meio de um cantar alto (incluindo letras acentuadas) em direção ao objeto, mas esta pronunciação "pública" das canções mágicas é quase exclusivamente realizada durante a noite no contexto dos rituais ayawaska.

Para além de "cfacearregar" um objeto ou substância, cantar diretamente para um paciente (ou vítima) é outra opção, na maioria das vezes realizada durante as sessões ayawaska. O ritual noturno começa pela ingestão da droga pelo curandeiro (médico). Depois disso, ele espera até que a droga faça efeito e, em seguida, começa a cantar. Em contextos Shipibo, geralmente, são usadas músicas de três categorias definidas pela sua forma musical: bewá (que deriva de músicas artísticas com um modelo melódico descendente específico em duas secções), mashá (que deriva de música da

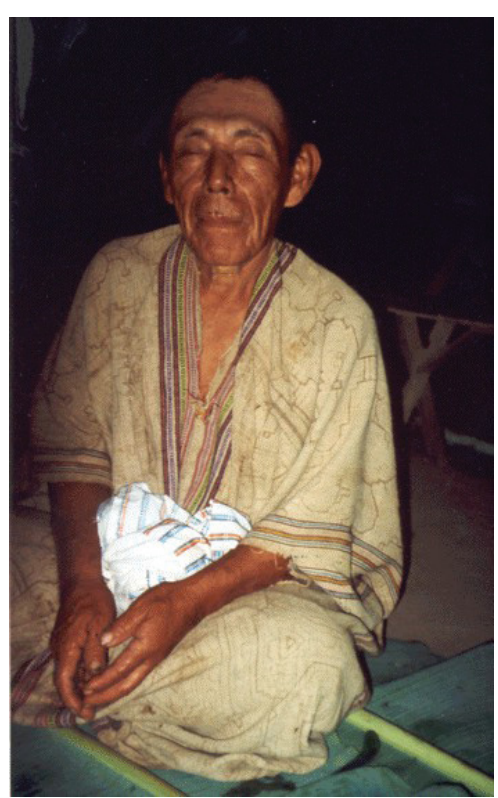

Figura 1: O médico Armando Sánchez Valles, durante uma sessão ayawaska. Foto original tirada por [autor, fecha] em San Salvador (distr. Yarinacocha, prov. Coronel Portillo, dept. Ucayali, Peru) Fonte: Fotografia do autor, 11 mar. 2001 
dança de roda cantada em festas de bebida, com um secção estrita repetida e um consequente ritmo de quatro batidas) e ikaro (importado da Kichwa-, Kukama- e de colonos de língua espanhola, juntamente com o uso de ayawaska, com diferentes caraterísticas melódicas e rítmicas; as músicas ikaro são exclusivamente realizadas em sessões ayawaska). A forma musical pode variar de acordo com cada nova canção; a forma escolhida depende do cantor. Alguns médicos podem cantar mais músicas do tipo ikaro, outros podem cantar principalmente bewá. Em qualquer caso, o médico irá diretamente cantar para os pacientes e ouvintes (que não ingerem a droga), às vezes durante seis horas seguidas, até que toda a cura seja feita, ou até que os efeitos da droga ( pae) se esvaneçam. Se estiver presente mais que um médico, podem cantar as suas músicas uma atrás da outra em uníssono ou, simultaneamente, em polifonia.

Uma terceira possibilidade para a aplicação da música em rituais de cura é a configuração mais comum quando os ocidentais tomam parte na sessão: não apenas os medico(s) ingerem ayawaska, mas também os participantes, ou pacientes. Nesses casos, o curandeiro geralmente eleva a voz da mesma forma como já foi descrito mas, às vezes, os participantes podem começar cantarolando, assobiando ou tentando seguir canção do curandeiro em uníssono. Às vezes, “os estudantes avançados" podem cantar ou executar suas próprias canções simultaneamente com a canção do curandeiro - assim, os ocidentais que beberam ayawaska assumem a posição de um outro médico presente no ritual. Mais importante ainda, como todos os participantes sofrem os efeitos da ayawaska, a música é considerada uma linha auditiva de ameaça de Ariadne para orientar a experiência visionária ao invés de uma ferramenta para realmente se comunicar com os não-humanos. O termo comum usado na literatura para se referir a estruturas semelhantes de rituais de cura é "xamanismo Ayawaska".

Em todos os três casos um médico assobia ou canta determinadas sequências musicais escolhidas, a fim de obter determinados resultados ou efeitos. Não existe uma relação óbvia ou linear entre a forma musical (bewá, mashá, ou ikaro), a linha melódica, o ritmo ou dinâmica e a intenção do medico, (por exemplo, convocando aliados, apelando para as forças divinas, afugentando as influências negativas, limpando as partes 
doentes do corpo, ou lutando contra curandeiros ou feiticeiros inimigos). Em vez disso, cada médico aprendeu um determinado repertório de melodias. Essas melodias, ou temas, podem ser tiradas de canções fora do contexto de cura. Também podem ter sido aprendidas ou adotadas por meio de um professor (geralmente um membro da família: pai, avô ou tio) ou, finalmente, podem ter sido feitas pelo próprio médico. Consequentemente, cada médico utiliza um repertório diferente de melodias. O estilo de cantar também difere de um indivíduo para o outro. Alguns cantam num registo muito agudo, por exemplo, alguns preferem uma intensa nasalização, alguns cantam num tempo bastante rápido, e assim por diante, enquanto outros não o fazem. Apesar dessa aparente liberdade, pode-se estabelecer algumas generalizações na forma de cantar: Um cantar agudo e em falsete, por exemplo, indica que o cantor está em contato com seres divinos poderosos que se pensa que atuam em tons agudos e por isso é especialmente apreciado pelo paciente. Alguns cantores aplicam uma máscara de voz (cf. Olsen, 1996, p. 159), dependendo das entidades com que estão em contato, cantar em falsete pode não ser mais que uma das máscaras disponíveis. Nesses casos, uma entidade não humana parece emprestar sua voz para o cantor. Apesar da máscara, nós - o público - pode-se perceber a "canção traduzida", produzida pelo cantor, porque ele ainda usa a melodia e ritmo humano (estilo Shipibo) e, na maioria dos casos, pronuncia a linguagem humana (Shipibo) nas suas letras. Em ambos, a principal caraterística das letras de meditação na performance koxonti para "carregar" os objetos e as letras acentuadas, quando são dirigidas aos pacientes, é a nomeação das identidades não-humanas correspondentes, ou das qualidades que são atribuídas ao paciente. Para um desempenho adequado e eficaz, é necessária uma ligação direta e uma comunicação ativa entre o médico e as entidades não humanas. Isto é indicado pela voz mascarada, com o cantor imitando o estilo de canto dos correspondentes não-humanos. Somente o médico pode perceber o seu canto (cf. Brabec de Mori, 2007). A canção interpretada pelo médico aparece como uma "manifestação corporal - exterior de [...] conhecimento e poder" (Gow, 2001, p. 144). 


\section{Aparecimento da "Terapia Estética"}

As categorias de música e modalidades de desempenho descritas acima - "secular", "semimedicinal" e "medicinal" - representam uma arte precisa e uma certa habilidade. Os cantores têm que memorizar melodias e frases de texto comuns de seus professores ou de outros cantores na sua comunidade. A fim de cantar para uma cura, eles também têm de realizar longos retiros e jejuar, apreendendo assim como contatar os seres não humanos. Quando concluem o período de formação de um ano, devem ser capazes de contatar esses seres não humanos à vontade e cantar juntamente com eles, com a finalidade de curar (ou de infligir sofrimento).

Na literatura acadêmica, no entanto, as canções Shipibo não foram ainda analisadas em amplos estudos comparativos, mas têm sido muitas vezes apresentados em fragmentos e, por vezes, fora de contexto. Têm sido frequentemente realizadas traduções, apesar da falta de um profundo entendimento de metáforas e códigos dos seus tradutores ${ }^{10}$. Em muitos casos, essa análise foi integrada numa suposta "cosmologia Shipibo" (como se isso existisse no singular). Em seguida, vou mostrar o quão diferente é a função da música que foi interpretada por outros estudiosos, a fim de sublinhar como o poder da compreensão da história intervém com a prática atual - e, consequentemente, como ela pode criar práticas.

Para começar, os padrões visuais kené chamaram mais a atenção de muitos visitantes do que as músicas, talvez devido à predominância da percepção visual na vida ocidental. Vários estudiosos tentaram interpretar, comparar e compreender o significado dos desenhos elaborados que as mulheres Shipibo produzem na cerâmica e têxteis, e que os homens costumavam esculpir em artigos de madeira. Os primeiros etnólogos aplicaram a Kulturkreislehre, herdada do século XIX, ou uma compreensão da difusão transcultural em geral. Tessmann (1928) aponta, desrespeitosamente, que os Shipibo apenas imitam um estilo artístico inventado antes por "civilizações superiores" e, portanto, não entendem nada do significado de sua própria arte. Durante o século $\mathrm{XX}$, os desenhos foram constantemente sujeitos a interpretações e raramente foi seriamente considerado que eles poderiam realmente ser 
"apenas" l'art pour l'art - a chamada Naturvölker não deveria produzir arte sem função. Angelika Gebhart-Sayer (1986) também se agarra à ideia de que um significado original assumido tinha há muito sido perdido e apenas alguns "xamãs" (Schamanen) ainda sabiam interpretar esses códigos antigos. Baseado nesses códigos fitícios, ela tenta encontrar uma ligação entre estes projetos, a ingestão de ayawaska e o desempenho de cantos de cura; a sua hipótese torna-se clara a partir do título: "una terapia estética".

Com essa "terapia estética", Gebhart-Sayer assume que "os xamãs" poderiam executar certas canções dedicadas a obter certas visões de desenhos kené durante a sua experiência ayawaska. Da mesma forma, quando se olha para desenhos pintados ou bordados, eles poderiam cantar melodias correspondentes, reproduzindo o código oculto nos padrões de desenho. Esses "desenhos cantáveis" ou "padrões de canto" poderiam, como Gebhart-Sayer argumenta, desempenhar um papel importante nas sessões de cura: na sua visão, o curandeiro perceberia os "padrões corporais" yora kené ( também invisíveis) que cobriam o corpo do paciente. Os "Padrões corporais" de uma pessoa doente iriam aparecer distorcidos. O curandeiro cantaria então a música adequada, a fim de convocar os padrões correspondentes que, posteriormente, apareceriam no corpo do paciente. Isto resultaria na cura. Surpreendentemente esta hipótese, que foi considerada uma ideia especulativa europeia e, portanto, carece de qualquer evidência na prática passada ou recente entre os Shipibo (Brabec de Mori; Mori Silvano de Brabec, 2009a; 2009b), poderia mais tarde ser observada como uma prática no campo e entrou em relatos etnográficos, por exemplo, por Martin (2005) ou Rittner (2007).

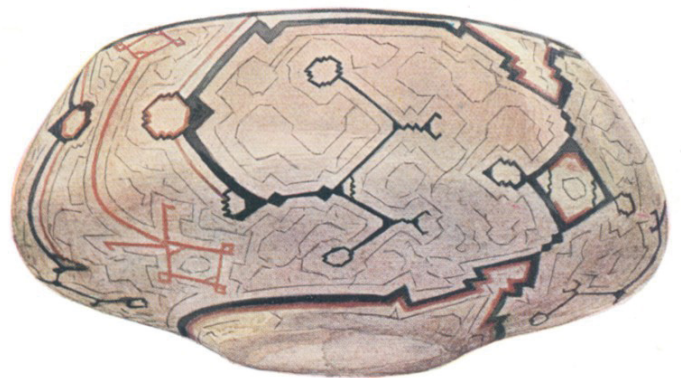

Figura 2: Vaso cerâmico para beber (kempo) pintado com kené, de cerca de 1925 Pintura com tinta de água de Tessmann (1928: 136f. Tafel IV (detalhe))

Fonte: Tessmann (1928) 


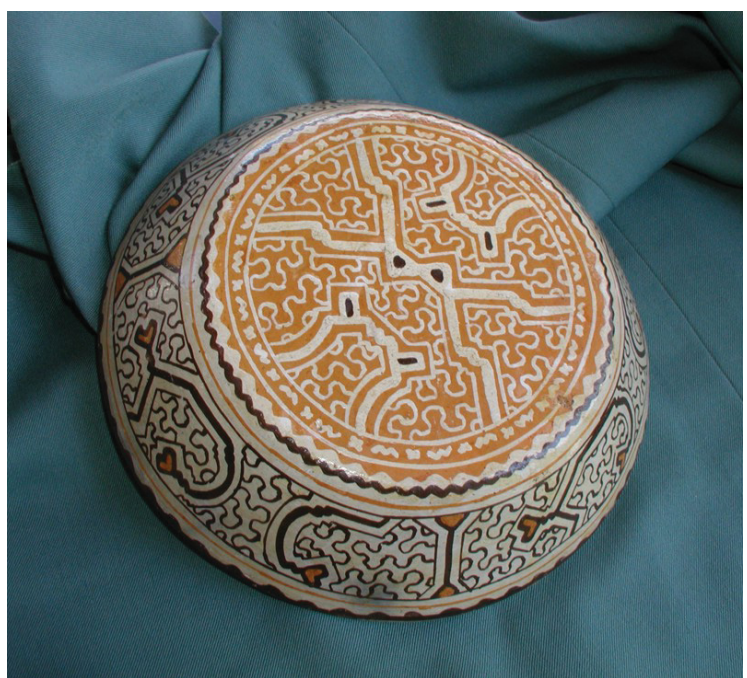

Figura 3: Kempo pintado por volta do ano 2000, feito para ser vendido no mercado turístico, com o atual "padrão" kené; note-se a diminuição da complexidade em comparação com o vaso de 1925

Fonte: Pierre Urban, 2001 com autorização de uso

Esses autores apresentam os curandeiros que atualmente cobrem os seus pacientes com tecidos bordados antes de cantar as correspondentes "canções padrão" enquanto eles estão sob a influência de ayawaska. Nos seus relatórios, os "xamãs" bebem ayawaska juntamente com seus pacientes (ocidentais). Assim, eles utilizam uma técnica de cura que prontamente explicam, com base em "padrões de cura", "canções de desenhos" e "visões de desenhos cantados", durante a influência da ayawaska. Esta prática pode ser observada, principalmente, na aldeia Shipibo de San Francisco de Yarinacocha perto da capital regional de Pucallpa, onde a maioria dos turistas e pesquisadores inexperientes chegam para conhecer os Shipibo pela primeira vez.

As principais diferenças dessa técnica de cura musical para a que expus anteriormente são a predominância do visual com os desenhos kené, a indubitável maior importância da ingestão da ayawaska (incluindo os pacientes), e o desaparecimento de animais ou outras identidades não-humanas atribuídos a destinatários humanos. A propósito, como Gebhart-Sayer (1987, p. 275) argumentava as letras parecem ser bastante irrelevantes para suas "canções padrão". A fim de compreender como tais diferentes interpretações podem ter 
surgido, vou resumir agora alguns processos relevantes da mudança nas representações dos Shipibo do seu próprio mundo vivido durante as últimas décadas.

\section{A Invenção da Tradição}

Por volta de 1950, os Shipibo não tentaram, por qualquer meio, representar nada especialmente "indígena" nas suas vidas diárias. Pelo contrário, eles geralmente procuravam uma forma de vida na melhor posição disponível entre seus próprios costumes e a crescente dominante sociedade fluvial mestizo (ou peruana) ${ }^{11}$.

Desde então, no entanto, algumas mudanças nas relações nacionais e internacionais levaram a uma reindigenização da maioria dos grupos da floresta peruana. As principais causas foram: (i) os trabalhos missionário-linguísticos do Summer Institute of Linguistics (SIL, ativo em Yarinacocha perto de Pucallpa entre 1947 e 2002) com a sua ideologia conservadora, ativo entre a maior parte dos grupos indígenas; (ii) a reforma do território do Sistema Nacional de Movilización Social (SINAMOS) projeto sob o governo de esquerda do general Velasco no início de 1970, com a concessão de títulos de terras comunais exclusivamente para aldeias indígenas (Comunidades Nativas); (iii) o crescente interesse dos antropólogos nos nativos da Amazónia e, portanto, um confronto com perguntas, novas então para o povo, sobre "tradições", "mitos", ou "conhecimento dos anciãos"; e, finalmente, (iv) desde 1960, mas maciçamente desde 1990, uma invasão crescente de "turistas individuais", "eco-turistas", "investigadores espirituais", "turistas etnomédicos" e "curandeiros brancos" (Rose, 1992) que se espalharam pelo o território Shipibo, apesar de se concentrarem em San Francisco de Yarinacocha.

O enorme interesse, especialmente no Shipibo, de antropólogos e turistas pode ser explicado por meio da combinação dos seguintes parâmetros: a acessibilidade geográfica relativamente fácil, o uso "tradicional" de um fármaco alucinogénico, uma arte nativa elaborada (os padrões kené), esteticamente atraente até mesmo para os ocidentais ignorantes. Quanto ao ayawaska, um evento que foi crucial para fomentar esse interesse foi a publicação do popular livro The Yage Letters por 
Burroughs e Ginsberg em 1963. Além disso, os famosos livros de Castaneda (1968) e Harner (1972; 1973) atraíram muitos interessados em experiências com "drogas indígenas", às florestas peruanas e, portanto, ao povo Shipibo. ${ }^{12}$

Todas essas tendências ajudaram a mudar a posição social das pessoas indígenas de forma positiva em relação à população mestiça fluvial, que era quase totalmente ignorada. Essa posição favorável ficou, no entanto, apenas disponível para pessoas e aldeias que se declararam "indígenas" e que o mostravam, ao representar a sua "natividade" no uso da língua vernácula (para o SIL), na economia laboral comum (para a obtenção de títulos de terra pela SINAMOS), em estar muito bem informado sobre os itens indígenas (para os antropólogos), e na prática, de preferência "mística", "espiritual" ou mesmo "primitiva", de eventos espetaculares e impressionantes para os turistas - em suma: quanto mais "indígena" melhor.

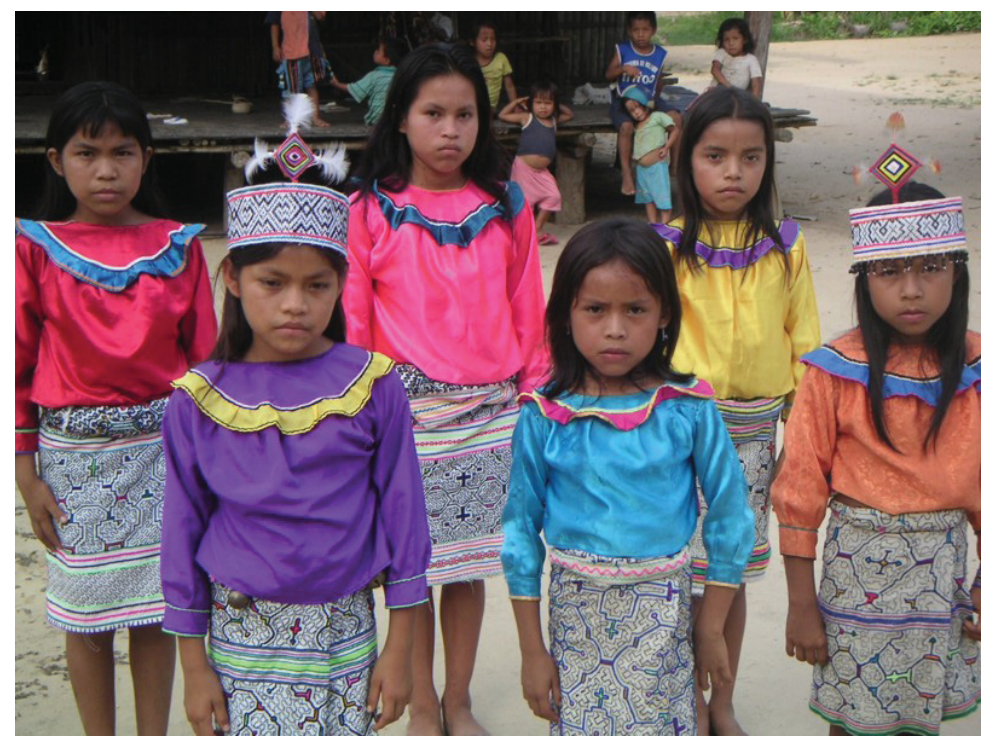

Figura 4:Estudantes representando a cultura indígena. Note-se, ao fundo, o trajo "normal" das crianças. Fotografia digital original de [autor, fecha] em Túpac Amaru (distr. Tahuanía, prov. Atalaya, dept. Ucayali, Peru)

Fonte: Fotografia do autor, 3 dec. 2004 


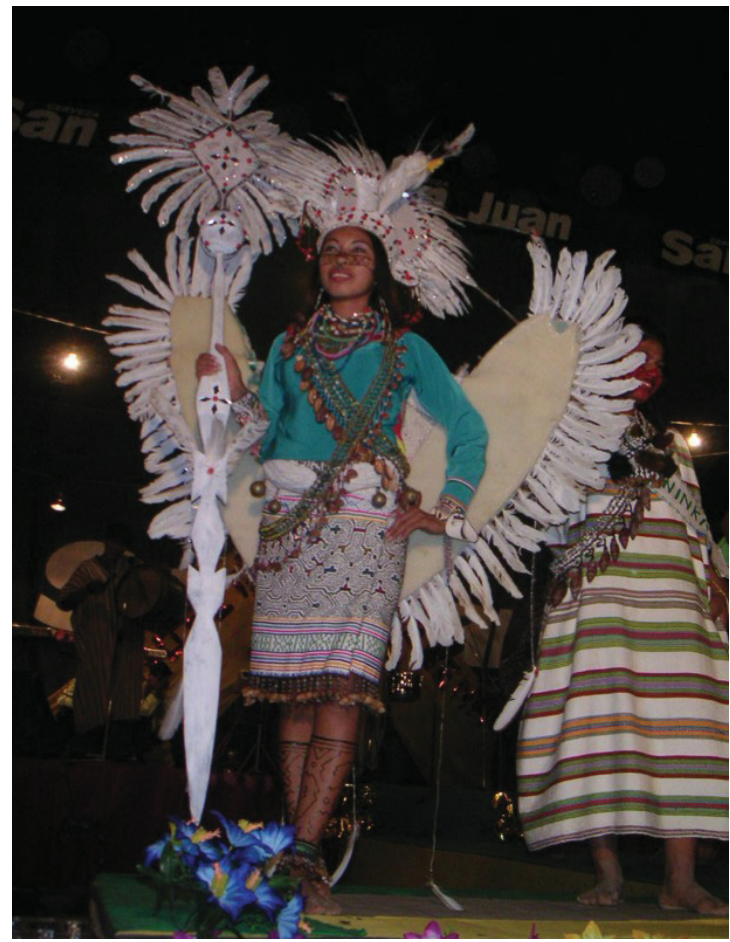

Figura 5: Candidata Shipibo no concurso "Miss Indígena". Esta "hiperindegenização" parece ser influenciada pela cultura popular Brasileira. Fotografia digital original de [autor, fecha] em Puerto Callao (distr. Yarinacocha, prov. Coronel Portillo, dept. Ucayali, Peru)

Fonte: Fotografia do autor, 31 jun. 2004

Em uma série de publicações,$^{13}$ minha esposa e eu temos contribuído para, empiricamente, mostrar quais os elementos da "cultura Shipibo" de hoje (que é um singular) que podem ser rastreados no passado e nas histórias de vários sub-grupos do Pano fluvial (que é um plural) no vale Ucayali, e cujos elementos podem ser entendidas como criações individuais (que é um plural) que hoje em dia são apresentados como "a tradição original do shipibo" (que é um singular). Parece que há muitos itens em mudança, que se perdem e que se criam, embora, entretanto, a ilusão da "tradição original do Shipibo" seja mantida pelos nativos, missionários, ONGs, pesquisadores e turistas num acordo mútuo surpreendentemente consistente. Todos ganham se a "tradição", sendo tão moderna quanto possível, ainda atinge o passado por meio dos "avós que já cantavam assim", "tradições autênticas ou originais do 
nosso povo", "elementos de uma cultura milenar", e aspectos similares. Essa terminologia é excessivamente utilizada pelos próprios povos indígenas. Especialmente em San Francisco de Yarinacocha, surgiu uma espécie de "escola" não - oficial, onde as pessoas fazem dinheiro com os visitantes: são os "chamanes" (homens), "artesanas" (mulheres), "artistas" (homens), "músicos/músicas" (homens ou mulheres) ou, nos casos mais promissores, uma combinação de todos ${ }^{14}$.

Os produtos em processo de mudança incluem, mas não se esgotam, na lista seguinte:

(i) as músicas mágicas ou medicinais fora do complexo ayawaska, como as que incluem performances teatrais e posse por animais, foram completamente abandonadas entre os Shipibo, canções de bebida e de namoro são hoje realizadas exclusivamente em apresentações para turistas pagantes.

(ii) O complexo ritual ayawaska foi rapidamente adaptado: o que antes era marginal e temido pelos nativos que não eram médicos obtiveram maior interesse por parte dos visitantes (e, portanto, presentes e dinheiro), e por isso este ritual foi relocalizado no centro da "cultura Shipibo". Não apenas o medico(s) iria beber a bebida, mas também todos os presentes, incluindo os visitantes. A experiência alucinatória coletiva foi declarada pelos Shipibo a forma "tradicional" para aplicar a medicina indígena.

(iii) Os desenhos kené foram adaptados para as estratégias de mercado e, portanto, simplificados em termos de complexidade e padronização (cf. Lathrap 1976, Mori Silvano de Brabec 2010, e ver as Figuras 2 e 3). As perguntas dos pesquisadores sobre possíveis significados dos desenhos foram refletidos pelos nativos, e muitos Shipibo começaram a dar respostas criativas para essas questões (Brabec de Mori; Mori Silvano de Brabec, 2009b, p. 112-114).

(iv) As músicas executadas durante as sessões ayawaska estavam ligadas aos complexos desenhos kené respondendo às perguntas de Gebhart-Sayer. Herlinda Agustin, em San Francisco de Yarinacocha, trabalhou com Gebhart-Sayer e agora é a prota- 
gonista mais importante em "padrões de cura", "padrões de canto", e até mesmo "canções tecidas" (Martin, 2005).

(v) Esse pacote multimédia combinado foi, assim, declarado uma tradição milenar e explicado como "a antiga tradição do Shipibo" (que é, mais uma vez, um singular): por outras palavras, a (adaptada) sessão de beber ayawaska, a (esteticamente renovada) arte kené, e as músicas (não existentes) que evocam projetos, ou projetos que codificam as músicas, são referidas como já existentes.

\section{A Estruturação do Tempo}

Na maior parte das sociedades indígenas da Amazónia, "tradição", "originalidade", "autenticidade", "história" e termos similares não podem ser expressos em língua vernácula. Há muitos indícios de que a estruturação do tempo nas línguas indígenas Amazónicas não segue, necessariamente, uma ideia linear ou até mesmo circular de uma progressão temporal. Gow (2001), por exemplo, dedicou um livro inteiro para explicar como o povo Yine usa estruturas narrativas ("mitos") para obliterar o tempo (em um sentido de Lévi-Straussiano) e para a construir histórias flexíveis. Entre os Yine, bem como entre os Shipibo, uma narração "mítica" é definida pelo uso de certas formas discursivas e gramaticais - ver Illius (1999, p. 126-164), totalmente relacionadas com aspectos de afastamento ou a evidencialidade (Valenzuela, 2003, p. 37-42). Nos Shipibo, alega-se que a expressão para indicar o passado "mítico" ou "remoto" pode ser encontrada em verbos com o marcador -ni. Nos exemplos que se seguem, a ação ocorreu, obviamente, num longo tempo "remoto" antes do discurso.

\footnotetext{
(1) Moa-tian-ra nocon papa-shoco nii meran ca-ni-que já-quando-DIR.Ev meu pai-DIM Floresta dentro Ir -ni-CMPL

'Há muito tempo, o meu avô foi para a floresta'

(de Faust 1990 ['1973]: 45 ["Mucho antes, mi abuelo se ha ido al monte"], interpretação minha)
} 
No exemplo (2), estamos perante um caso de passado "mítico" onde -ni é utilizado juntamente com indicadores narrativos (aqui: nete benatianronki).
(2) Nete bena-tion
mundo novo-T
ja-pao-ni-ke $[. .$.
vivo-HAB-REM.P-CMPL
'When the world was new, our ancestors lived just suffering $[\ldots]$ '
(em Valenzuela 2003: 38, interpretação original)

Nos Shipibo, no entanto, o assim chamado "controlo remoto" ou passado "mítico" pode ser descrito, mais precisamente, como um nãofuturo remoto (ou extraexperimental). Ou seja, ele abrange não apenas os eventos relatados como tendo ocorrido muito antes do tempo real de expressão, mas estende-se também a eventos ou estados que são contemporâneos com a altura em que o discurso foi feito, ao mesmo tempo que se obtinha um nível além da percepção quotidiana comum. Considere o seguinte exemplo (3) a partir de uma canção de cura, onde tsakani 'permetrar' não se refere a um evento de um passado remoto e mítico, mas para um que ocorreu pouco antes da hora do discurso:
(3) $\min \quad x a m a$ tsaka-ni
/ tsaka-ni

a vossa essência/culminação penetrar-REM.NONFUT penetrar-REM.NONFUT $i-k e n-b i$ I pisha-aketan-a

fazer/ser-depois-EMPH soltar-todos.em redor de-CMPL.PART 'como a sua essência foi penetrada soltei-a em todos os lados'15

Nesse exemplo, xama refere-se a um aspecto do corpo do paciente, que não é diretamente percetível. Esse aspecto do corpo está agora num estado vulnerável, pois foi "penetrado" recentemente por meio de feitiçaria. Isto é, o uso do -ni aqui não indica afastamento no tempo, mas sim um afastamento da experiência quotidiana.

Finalmente, no exemplo (4) (também a partir de uma canção de cura), boni-bo-kan 'tirar' refere-se, novamente, a um evento que não 
é acessível à percepção quotidiana. Nesse caso, no entanto, não é de todo localizado no passado, mas ocorrendo no momento de expressão:
(4)

$\begin{array}{llll}\text { roni(n)-man } & \text { kaya } & \text { bo-ni-bo-kan } & / \text { jawen } \\ \text { anaconda-tra } & \text { alma } & \text { tirar-REM.NONFUT-EMPH-MOD } & \text { dele/dela }\end{array}$
kaya-kaya-ki / kena-kena-bain-kin
alma-EMPH-REP chamar-chamar-mod-help
'(enquanto) a anaconda tira a sua alma, (eles estão a ajudar-me) chamando-a'

De acordo com Mori Silvano de Brabec (comunicação pessoal, 20 de novembro de 2010), o uso de -ni como um indicador de uma contemporaneidade distante limita-se a discursos ou músicas de médicos durante a performance ritual. ${ }^{16}$ Que o -ni participa na expressão de adicional estados ou eventos experienciais já foi reconhecido por Illius (1999, p. 128):

E, talvez, o sufixo-paonique, que indica o plano temporal da maioria dos mitos, não indique não apenas o passado mais remoto mas, ao mesmo tempo, um presente ubíquo, atemporal, equivalente a um estado de transformação, uma forma "potencial" de existência . Podemos perfeitamente tentar não considerar as formas verbais em -qui, ni-,nique e, especialmente, -paonique, que até agora têm sido entendidos e descritas como "tensas", tão tensas como, ou de aparência tensa [...], mas como um "estrato de realidade," $[\ldots] .{ }^{17}$

Daqui resulta que as formas gramaticais envolvendo -ni não indicam necessariamente o passado. De qualquer forma, o aspecto extraexperimental que se aplica a ambos os discursos "mítico" e "mágico" (narração ou música) leva à conclusão de que ambos não são permanentes. Parece que a utilização de um não futuro remoto em linguagem Shipibo permite, resumindo, a possibilidade de duplicação, transformação e bifurcação para alterar o respetivo conteúdo, dependendo da posição do sujeito falante. Considerando esses pensamentos, o discurso Shipibo sobre o passado ("tradição", "originalidade", e assim por diante) inclui, 
necessariamente, a possibilidade de mudança, da mesma forma que o presente ("este mundo", "a doença do paciente", e assim por diante) permite a alteração ou manipulação no curso das ações dos médicos para a cura ou feitiçaria.

\section{Conclusões}

Na primeira parte deste artigo, realizei uma pesquisa do poder construtivo da música em diferentes contextos, como ("secular") canções de bebida ou canções de amor ("semi-medicinal") canções de poder ou certos efeitos culturais e canções mágicas ou medicinais performadas com ou sem a ingestão de ayawaska. Isso foi comparado a uma interpretação mais popular da cura musical de Shipibo, a "terapia estética", que envolve os desenhos kené. Então analisei como uma identidade "tribal" e uma "tradição" coletiva poderia emergir durante o século XX entre os Shipibo. Finalmente, foi investigada a função do sufixo -ni na língua Shipibo. Os resultados mostram que o passado e o presente não são tão claramente distintos como, por exemplo, nas línguas europeias. Tanto a música como um processo mágico baseado em recursos que estão localizados num presente extraexperimental (como um mundo paralelo ou "estrato da realidade") e a narrativa (como um processo construtivo baseado em recursos localizados no passado) são capazes de manipular a posição de um sujeito (por exemplo, social ou económica) e a condição (por exemplo, psicológica ou física) durante a presente situação e, consequentemente, para o futuro.

A ideia de um passado flexível que permite histórias diferentes e mutáveis é perfeitamente adequada para a estruturação de tempo que não faz separar, a priori, o passado do presente. Um passado que está presente (ainda que, em qualquer caso extraexperimental) não contradiz experiências quotidianas de, por exemplo, pessoas (ou o mundo como tal) a envelhecer, mas simplesmente incorpora um passado que é tão desprendido como o futuro dentro do conceito de tempo. A presença imanente do passado e do futuro não é, portanto, sentida diretamente, mas localizada em regiões distantes embora reais. Dentro desses "estratos da realidade" remotos, tempo e espaço - passado, presente e futuro, aqui e lá - não estão separados. Isso é bem conhecido 
em muitas descrições de cosmologias "xamânicas"18. Só os especialistas treinados (médicos) têm acesso e podem visitar essas regiões remotas e qualquer manipulação dessas regiões e as transformações resultantes ou efeitos sobre a vida quotidiana só podem ser realizadas ou cantando ou por uma narrativa formalizada.

Por outro lado, a inevitabilidade histórica da interpretação ocidental comum do tempo não é compatível com este modelo de passado não fixo. Assim, surge um conflito quando se interpretam processos de mudança histórica dentro de um grupo indígena. Esse conflito foi profundamente analisado por Gow (2001, p. 14-19, e noutras partes). Um compreensão ocidental "ortodoxa" da maioria dos processos de mudança faz com que os povos indígenas aparecem muito passivos, e reagindo da mesma forma à força intrusiva do mundo globalizado. No entanto, uma compreensão mais profunda da estruturação indígena do tempo revela que o seu papel é muito mais ativo. Em algumas situações, como foi demonstrado neste trabalho, em vez disso, eles estão muito à frente, com os ocidentais lutando para reagir às suas inovações, como aos antropólogos (incluindo eu) perpetuamente investigando e fazendo-lhes perguntas estúpidas para finalmente descobrir o seu "real" passado - enquanto muitos Shipibo fazem pouco de nós ${ }^{19}$.

Os protagonistas Shipibo que hoje executam músicas que podem ser transformadas em projetos e vice-versa estão, é claro, inventando isso a partir de sucata (ou mais precisamente, foi a antropóloga GebhartSayer que o inventou). No entanto, tendo em vista a sua prática atual e sua atribuição de um novo significado para a dimensão flexível do "passado remoto", declarando que era assim "a tradição original dos Shipibo", essa ideia está realmente a ser transformada em realidade. Os visitantes podem observar hoje em dia esta prática, embora ainda quase exclusivamente em San Francisco de Yarinacocha. No entanto, acho que a prática se espalhará mais entre os Shipiho num futuro próximo, simplesmente porque ela vende muito bem. A estruturação do tempo e da distância no entendimento do Shipibo permite total liberdade na manutenção, transmissão, criação e alteração da "tradição", da mesma forma como uma situação presente pode ser manipulada magicamente por médicos especializados por meio da forma correta de cantar. A história está em construção. 


\section{Lista de Abreviações}

$\begin{array}{ll}\text { 1PL } & \text { Primeira pessoa do plural } \\ \text { ABS } & \text { absolutivo } \\ \text { CMPL } & \text { aspecto completivo } \\ \text { DIM } & \text { diminutivo } \\ \text { DIR.EV } & \text { de prova evidente } \\ \text { EMPH } & \text { ênfase } \\ \text { GEN } & \text { genitivo } \\ \text { HAB } & \text { habitual } \\ \text { MOD } & \text { modificator } \\ \text { PART } & \text { particípio } \\ \text { PL } & \text { plural } \\ \text { REM.NONFUT } & \text { Não futuro remote } \\ \text { REM.P } & \text { passado remoto } \\ \text { REP } & \text { relatado } \\ \text { SSSI } & \text { evento simultâneo, o mesmo assunto, clausula matriz intran- } \\ \text { TEMP } & \text { sitiva } \\ \text { TRA } & \text { advérbio temporal } \\ & \text { tradutor, intransitivo para transitivo } \\ & \end{array}$

\section{Notas}

1 O trabalho de campo (2001-2007) que está na base desta comunicação foi realizado com a ajuda da University of Vienna (três bolsas de viagem), o British Centre em Pucallpa, a Austrian Academy of Sciences (programa "DOC") e a Austrian Association for Parapsychology. Gostava de agradecer ao Christian Huber pelo contributo essencial com a sua experiência linguística, a Bruno Illius e a Laida Mori Silvano de Brabec pela sua ajuda.

2 Para citar apenas alguns dos autores mais influentes, cf. Lathrap (1970; 1976) ou Myers (2004 [ ${ }^{12002]}$ ) em arqueologia; de Girard (1958) a Roe (1982) ou Illius (1987, 1999) em antropologia; Faust (1990 [ ${ }^{1} 1973$ ]) ou Valenzuela (2003) em linguística; de Baer (1971) a Tournon (2002) em etnomedicina e etnobotânica; e de Karsten (1955) a Jervis (no prelo) no uso da ayawaska entre os Shipibo. Para uma visão Pan-Amazónica e informação detalhada acerca da preparação, uso e efeitos da ayawaska ver Labate \& Araújo (2004).

3 "Compreensão Ecológica" refere-se a um cosmos multi-natural com a possibilidade de uma comunicação inter-espécies (perspetivismo) como foi formulado por Viveiros de Castro e outros (1997). Aqui, "ecológico", define a caraterística da rede de comunicação em vez de uma vida romântica embutida na natureza, como é sugerido politicamente por "ecologia" nos países industrializados. 
4 Cf. Gow (1994, p. 109) para os Yine, ou os meus estudos mais recentes com os Kakataibo and Iskobakebo em [autor, referência]

5 Hoje, está provado ser utilizada na performação mágica a música exclusivamente vocal e alguma percussão (como o shapaja, um maço de folhas). Illius (1987, p.126, 157) afirma que entre os Shipibo dos tempos antigos o arco musical jonoronati também serviu para a comunicação entre médico e não humanos. Esse instrumento já não é utilizado.

6 Em [autor, referência] é feita uma análise mais detalha das letras das canções dos Shipibo e a inerente codificação do comportamento.

7 Ver a as referências a mochai ou termos similares em Cárdenas Timoteo (1989, p. 125), por Diaz Castañeda (1923, citado em Tournon 2002, p. 182) ou nos volumes de Izaguirre (1922-1929, citados em Wistrand Robinson 1969, p. 483), entre alguns outros. Para saber mais detalhes, ver Brabec de Mori (201 la, p. 447-464).

8 Gravei onze canções mochai e descrevi três categorias, ou finalidades, do canto mochai: (i) adoração ao nascer do Sol, ou Sol "curativo" ou à Lua durante um eclipse; (ii) Uma cerimónia religiosa de oração coletiva que não é essencialmente direccionada para o Sol, mas sim para o encontro com seres poderosos como o inka e seus pares, os simpibo jonibo, e (iii) a aplicação de canções mochai dentro de rituais de cura, a fim de realizar, especialmente, as difíceis tarefas de curar (ver [autor, referencia]).

9 Utilizo formas masculinas quando me refiro aos curandeiros, porque na minha pesquisa, 93\% dos curandeiros eram do sexo masculino. As mulheres também desempenham tarefas importantes nos sistemas médicos na Amazónia Ocidental, mas raramente se envolvem como médicas que realizam curas cantando e entrando em contato com seres não humanos.

${ }^{10}$ Quero aqui excluir o trabalho de Illius (1987; 1997; 1999), que se destaca pela positiva. Illius traduziu e analisou não apenas uma ampla coleção de canções "xamânicas", mas também o diálogo sobre canto e uma série de canções não relacionadas com a cura (ver Illius, 1999, p. 208).

${ }^{11}$ López Caballero (2008) analisa um processo similar entre a população indígena Mexicana. Argumenta o autor que, durante a revolução Mexicana, este grupo não apresentava nenhuma identidade "Indígena", e a sua interpretação do seu próprio passado era, na altura, quase contrária à sua narrativa histórica tal como era contada depois do movimento indigenismo.

12 Para mais detalhes acerca desse processo, ver Brabec de Mori e Mori Silvano de Brabec (2009b) e Brabec de Mori (2013).

13 Ver [autor, duas referências]

${ }^{14}$ Os especialistas Shipibo na utilização da ayawaska são, na sua maioria, homens (93\% na minha pesquisa).

Apenas recentemente têm ocorrido algumas "questões de género" (provavelmente desencadeadas pelas preferências dos turistas), e estão a aparecer ayahuasqueras femininas (cf. Jervis, no prelo, consultar também < http://www.templeofthewayoflight.org >, acesso em: 20/11/2010)). Todos os especialistas no uso do ayawaska que trabalham no contexto indígena identificam-se como médicos (usando, por empréstimo, esta palavra espanhola para substituir termos vernaculares como yobé ou meraya). Se, por outro lado, eles se identificam como chamanes, isto indica, de forma bastante segura, que eles pretendem trabalhar com os visitantes ocidentais. Mais adiante, é muito interessante ver a distinção entre artesãs e artistas (cf. Brabec de Mori; Mori Silvano de Brabec, 2009a): As artesãs femininas produzem "artesanato", um tecido bordado de tamanho médio, vendido a cerca de USD 35, enquanto os 
artistas, masculinos, produzem pinturas, "arte", que são vendidas a cerca de USD 350 cada (preços de 2008), embora os investimentos médios em trabalho, material e criatividade sejam bastante semelhantes. Esta distinção entre "arte" e "artesanato" é uma recente importação ocidental (antes de, por volta de, 1995, os pintores de arte estavam ausentes entre os Shipibo) o que lança uma sombra duvidosa sobre a igualdade de género assumida na sociedade ocidental.

15 Os exemplos (3) e (4) foram retirados dos dados recolhidos no meu trabalho de campo guardados no [signatura de archivo].

${ }^{16}$ Em muitas canções dos médicos o -ni é utilizado sem o conclusivo marcador de orientação -ke (ver Ex. (3) e (4)). No entanto, no discurso quotidiano, ambos os sufixos são quase sempre usados combinados (ver Ex. (1) e (2)). No caso dos verbos que terminam em -ni (Ex. (3)), a ocorrência de um não-futuro remoto (exclusivamente na fala dos medicos') tem que ser cuidadosamente distinguida pelo contexto da terminação - $n-i$ (que também ocorre no discurso quotidiano) que é uma sucessão do sufixo tradutor - $n$ e o sufixo modificador $-i$ indica intenção ('a fim de').

17 Texto original em alemão: “Und vielleicht ist das Suffix -paonique, das die Zeitstufe der meisten Mythen kennzeichnet, nicht nur die fernste Vergangenheit, sondern gleichzeitig ein zeitloses, allgegenwärtiges Präsens; gleichzusetzen etwa mit einem Verwandlungszustand, einer "möglichen“ Existenzform. Man könnte sehr wohl versuchen, die bisher als „Zeitstufen “verstandenen und bezeichneten Verbformen auf -qui, -ni, -nique und vor allem -paonique nicht mehr als Tempus oder Tempus-Aspekt aufzufassen [...], sondern als eine "Realitätsstufe“ [...]."

18 Ver, por exemplo, a vasta (embora metodologicamente ultrapassada) coleção de descrições das viagens, por lugares remotos e tempos remotos, de shamans no estudo comparativo pioneiro realizado por Eliade (1997 [ $\left.\left.{ }^{1} 1951\right]\right)$.

19 Ver a conclusão e o apêndice em Brabec de Mori (2013, p. 231-235), onde são dados alguns exemplos engraçados e ao mesmo tempo embaraçosos de "diálogos escondidos" entre os vendedores e os artistas Shipibo.

\section{Referências}

BAER, Gerhard. Auskünfte eines Srahuanbo über schamanistische Vorstellungen seiner Gruppe (Ost-Peru). Anthropos, [S.l.], v. 66, n.1-2, p. 223-228, 1971.

BRABEC DE MORI, Bernd. The Inka's Song Emanates from my Tongue: Composition vs. Oral Tradition in Western Amazonian Curing Songs. Paper presented at the $39^{\text {th }}$ World Conference of the International Council for Traditional Music (ICTM), Vienna, July 2007.

BRABEC DE MORI, Bernd. Die Lieder der Richtigen Menschen: Kulturanthropologie der indigenen Bevölkerung und ihrer Musik im Ucayali-Tal, Westamazonien (tentative title). PhD thesis. Vienna: University of Vienna, 2011 a. 
BRABEC DE MORI, Bernd. Tracing Hallucinations: Contributing to an Ethnohistory of Ayawaska Usage in the Peruvian Amazon. In: JUNGABERLE, Henrik; LABATE, Beatriz Caiuby (Ed.). The globalization of the uses of Ayahuasca. Göttingen etc.: Hogrefe, 201 lb.

BRABEC DE MORI, Bernd. La transformación de la medicina ShipiboKonibo. Conceptos etno-médicos en la representación de un pueblo indígena. Estudios del Hombre, [S.l.], v. 30, p. 203-243, 2013. (Etnografías de América Latina, editado por Eveline Sigl, Yvonne Schaffler y Ricardo Ávila).

BRABEC DE MORI, Bernd; BRABEC, Laida Mori Silvano de. ShipiboKonibo Art and Healing Concepts: A Critical View on the 'Aesthetic Therapy. Viennese Ethnomedicine Newsletter, [S.l.], v. 11, n. 2-3, p. 18-26, 2009a.

BRABEC DE MORI, Bernd; BRABEC, Laida Mori Silvano de. La corona de la inspiración: Los diseños geométricos de los Shipibo-Konibo y sus relaciónes con cosmovisión y música. Indiana, [S.l.], v. 26, p. 105-134, 2009b.

BURROUGHS, William S.; GINSBERG, Allen. The Yage Letters. $2^{\text {nd }}$ ed. San Francisco: City Lights Books, 1975 [ $\left.{ }^{1} 1963\right]$.

CÁRDENAS TIMOTEO, Clara. Los Unaya y su Mundo: Aproximación al Sistema Médico de los Shipibo-Conibo del Río Ucayali. Lima: CAAAP, 1989.

CASTANEDA, Carlos. The Teachings of Don Juan: a Yaqui Way of Knowledge. New York: Ballantine Books, 1968.

ELIADE, Mircea. Schamanismus und archaische Ekstasetechnik. (suhrkamp taschenbuch wissenschaft, 126). $9^{\text {th }}$ ed. Frankfurt am Main: Suhrkamp, $1997\left[{ }^{1} 1951\right]$.

FAUST, Norma. Lecciones para el aprendizaje del idioma ShipiboConibo. (Documento de trabajo ,1). $2^{\text {nd }}$ ed. Yarinacocha: Ministerio de Educación and ILV, $1990\left[{ }^{1} 1973\right]$.

GEBHART-SAYER, Angelika. Una terapia estética: Los diseños visionarios del ayahuasca entre los Shipibo-Conibo. América Indígena, [S.l], v. 46, n. 1, p. 189-218, 1986.

GEBHART-SAYER, Angelika. Die Spitze des Bewußtseins:

Untersuchungen zu Weltbild und Kunst der Shipibo-Conibo. (Münchener Beiträge zur Amerikanistik, 21). Hohenschäftlarn: Renner, 1987.

GIRARD, Rafael. Indios selváticos de la Amazonía Peruana. México: Libro Mex, 1958. 
GOW, Peter. River people: Shamanism and History in Western Amazonia. In: THOMAS, Nicholas; HUMPHREY, Caroline (Ed.). Shamanism, History and the State. Ann Arbor: University of Michigan Press, 1994. p. 90-113.

GOW, Peter. An Amazonian Myth and its History. Oxford: Oxford University Press, 2001.

HARNER, Michael. The Jivaro: People of the Sacred Waterfalls. Los Angeles: University of California Press, 1972.

HARNER, Michael (Ed.). Hallucinogens and Shamanism. New York: Oxford University Press, 1973.

ILLIUS, Bruno. Ani Shinan: Schamanismus bei den Shipibo-Conibo (OstPeru). (Ethnologische Studien, 3). Tübingen: Verlag S \& F, 1987.

ILLIUS, Bruno. Ein Lied zur Haarschneidezeremonie der Shipibo-Conibo. In: DÜRR, Eveline; SEITZ, Stefan (Hg.). Religionsethnologische Beiträge zur Amerikanistik. (Ethnologische Studien, 31). Münster: LIT, 1997. p. $211-231$.

ILLIUS, Bruno. Das Shipibo: Texte, Kontexte, Kommentare. Ein Beitrag zur diskursorientierten Untersuchung einer Montaña-Kultur. Berlin: Reimer, 1999.

JERVIS, Francis (forthcoming). How do you tell the joshobo that their shinan is coshima? Translation and transculturality in ethnomedical tourism. 20 p. [MS]

KARSTEN, Rafael. Los Indios Shipibo del Río Ucayali. Revista del Museo Nacional, [S.l.], v. 24, p. 154-173, 1955.

LABATE, Beatriz Caiuby; ARAÚJO, Wladimyr Sena (Ed.). O uso ritual da ayahuasca. $2^{\text {nd }}$ ed. Campinas: Mercado de Letras, 2004.

LATHRAP, Donald W. The Upper Amazon. (Ancient Peoples and Places, 70). New York: Thames and Hudson, 1970.

LATHRAP, Donald W. Shipibo Tourist Art. In: GRABURN, Nelson H.H. (Ed.). Ethnic and Tourist Arts: Cultural Expressions from the Fourth World. Berkeley: University of California Press, 1976. p. 197-207.

LÓPEZ CABALLERO, Paula. Which heritage for which heirs? The preColumbian past and the colonial legacy in the national history of Mexico. Social Anthropology, [S.l.], v. 16, n. 3, p. 329-345, 2008. [= Special issue: Colonial legacies. Guest editor: Benoît de L'Estoile] 
MARTIN, Barrett H. Woven Songs of the Amazon (Icaros and Weavings of the Shipibo Shamans). Paper presented at the $50^{\text {th }}$ Conference of the Society for Ethnomusicology (SEM), Atlanta, USA, November 2005. Disponível em: < < http://www.museumtextiles.com/wovensongs.pdf $>$. Acesso em: 20 jul. 2010). [MS]

MORI SILVANO DE BRABEC, Laida. El arte indígena invisible: Como el arte atual construye a la historia. Paper presented at the 5. Treffen deutschsprachiger Lateinamerika- und KaribikforscherInnen. Marburg, Germany, October 2010. [MS]

MYERS, Thomas P. Looking Inward: the Florescence of the Conibo/Shipibo Art During the Rubber Boom. In: MYERS, Thomas P.; CIPOLLETTI, María S. (Ed.). Artifacts and Society in Amazonia/Artefactos y sociedad en la Amazonía. (Bonner Amerikanistische Studien, 36). $2^{\text {nd }}$ ed. Bonn: BAS, 2004 [ $\left.{ }^{1} 2002\right]$. p. 127-142.

OLSEN, Dale A. Music of the Warao of Venezuela: Song People of the Rain Forest. Gainesville: University Press of Florida, 1996.

RITTNER, Sabine. Sound - Trance - Healing - The sound and pattern medicine of the Shipibo in the Amazon lowlands of Peru. Music Therapy Today, [S.l.], v. 8, n. 2, p. 196-235, 2007. Disponível em: < http:// musictherapyworld.net>. Acesso em: 20 jul. 2010.

ROE, Peter G. The Cosmic Zygote: Cosmology in the Amazon Basin. New Brunswick: Rutgers University Press, 1982.

ROSE, Wendy. The great pretenders: further refletions on whiteshamanism. In: JAIMES, M. A. (Ed.). The state of native America: genocide, colonization, and resistance. Boston: South End Press, 1992. p. 403-421.

TESSMANN, Günter. Menschen ohne Gott: Ein Besuch bei den Indianern des Ucayali. (Veröffentlichung der Harvey-Bassler-Stiftung: Völkerkunde, 1). Stuttgart: Strecker \& Schröder, 1928.

TOURNON, Jacques. La merma mágica: Vida e historia de los ShipiboConibo del Ucayali. Lima: CAAAP, 2002.

VALENZUELA, Pilar M. Evidentiality in Shipibo-Konibo, with a comparative overview of the category in Panoan. In: AIKHENVALD, Alexandra Y.; DIXON, R. M. W. (Ed.). Studies in Evidentiality. (Typological studies in language, 54). Amsterdam: John Benjamins Publishing Co., 2003. p. 33-61.

VIVEIROS DE CASTRO, Eduardo. Die kosmologischen Pronomina und der indianische Perspektivismus. Societé suisse des Americanistes, Bulletin, v. 61, p. 99-114, 1997. 
Bernd Brabec de Mori

WISTRAND Robinson, Lila M. Music and Song Texts of Amazonian Indians. Ethnomusicology, [S.l.], v. 13, p. 469-488, 1969.

Recebido em 18/12/2017

Aceito em 30/04/2018 